\title{
1 Combustion of fuel blends containing digestate pyrolysis oil in a multi-cylinder 2 compression ignition engine
}

3 A. K. Hossain ${ }^{a}$, C. Serrano ${ }^{b}$, J. B. Brammer ${ }^{b}$, A. Omran ${ }^{b}$, F. Ahmed ${ }^{a}$, D. I. Smith ${ }^{a}$, P. A. Davies ${ }^{a}$

4 aSustainable Environment Research Group, School of Engineering and Applied Science, Aston University, Birmingham B4 7ET, UK

5 bEuropean Bioenergy Research Institute, School of Engineering and Applied Science, Aston University, Birmingham B4 7ET, UK

7 Abstract

8 Digestate from the anaerobic digestion conversion process is widely used as a farm land fertiliser. This study 9 proposes an alternative use as a source of energy. Dried digestate was pyrolysed and the resulting oil was 10 blended with waste cooking oil and butanol (10, 20 and 30 vol. \%). The physical and chemical properties of the 11 pyrolysis oil blends were measured and compared with pure fossil diesel and waste cooking oil. The blends were 12 tested in a multi-cylinder indirect injection compression ignition engine. Engine combustion, exhaust gas emissions and performance parameters were measured and compared with pure fossil diesel operation. The ASTM copper corrosion values for $20 \%$ and $30 \%$ pyrolysis blends were $2 \mathrm{c}$, compared to $1 \mathrm{~b}$ for fossil diesel. The kinematic viscosities of the blends at $40^{\circ} \mathrm{C}$ were 5 to 7 times higher than that of fossil diesel. Digested pyrolysis oil blends produced lower in-cylinder peak pressures than fossil diesel and waste cooking oil operation. The maximum heat release rates of the blends were approximately $8 \%$ higher than with fossil diesel. The ignition delay periods of the blends were higher; pyrolysis oil blends started to combust late and once combustion started burnt quicker than fossil diesel. The total burning duration of the $20 \%$ and $30 \%$ blends were decreased by $12 \%$ and $3 \%$ compared to fossil diesel. At full engine load, the brake thermal efficiencies of the blends were decreased by about 3 - 7\% when compared to fossil diesel. The pyrolysis blends gave lower smoke levels; at full engine load, smoke level of the $20 \%$ blend was $44 \%$ lower than fossil diesel. In comparison to fossil diesel and at full load, the brake specific fuel consumption (wt.) of the $30 \%$ and $20 \%$ blends were approximately $32 \%$ and $15 \%$ higher. At full engine load, the CO emission of the $20 \%$ and $30 \%$ blends were decreased by $39 \%$ and $66 \%$ with respect to the fossil diesel. Blends $\mathrm{CO}_{2}$ emissions were similar to that of fossil diesel; at full engine load, $30 \%$ blend produced approximately $5 \%$ higher $\mathrm{CO}_{2}$ emission than fossil diesel. The study concludes that on the basis of short term engine experiment up to $30 \%$ blend of pyrolysis oil from digestate of arable crops can be used in a compression ignition engine. 
In 2012, about $10 \%$ of the total world greenhouse gas emission came from the European Union [1]. Recently, the EU parliament has set a 2030 target of at least: (i) 40\% emission reduction compared to 1990 level, (ii) $27 \%$ energy share from renewables, and (iii) increasing energy efficiency by $27 \%$ [2]. Increased use of renewable biofuels, and energy recovery from waste streams from bioenergy conversion, would help to achieve the EU's 2030 target.

Anaerobic digestion (AD) is a well-known conversion process yielding biogas from organic biomass materials. The waste stream form the anaerobic digestion plant (known as digestate or slurry) contains soil nutrients (notably N, P and K). In the UK alone, AD plants generates approximately 277,000 tonnes/year of digestate [3]. The digestate is widely used as a fertiliser in farm land to release these soil nutrients $[4,5]$. However, the effectiveness of the digestate as fertiliser will depend on the type of biomass feedstock and processing parameters used. There is a concern about land spreading of digestate due to the possible heavy metals and pathogen content if not controlled properly [6-8]. Alternative uses of digestate have been investigated by several researchers [9-16] . A simulation study was carried out to study the feasibility of using the digestate sludge for incineration in a steam turbine plant [9]. It was reported that integrated AD-steam cycle system could meet up to $13-18 \%$ of the electricity demand of the whole AD plant. The authors mentioned that reducing the digestion period would enhance the quality of digestate and hence electricity production; but on the other hand, this would affect the production of biogas [9]. Besides incineration, pyrolysis and gasification of the AD digestate (and sludge) has also been investigated $[14,15]$. Shane et al. [14] investigated the quality of pyrolysis fuel products using a blend of saw dust and pig manure digestate as feedstock. The authors reported that addition of saw dust increased the net energy yield from biochar. Yue et al. [16] reported that $6.3 \mathrm{~m}^{3}$ of ethanol can be produced from 0.6 tonne of dry digestate fibre (obtained from 1 tonne of cattle manure used in the AD plant).

Pyrolysis can convert biomass and waste into liquid, solid and gaseous forms. All three fractions have potential as fuels in various types of prime mover for transport, power generation, and combined heat and power application. In this study, pyrolysis oil (organic liquid fraction) produced from anaerobically digested pellets will be examined as a fuel for diesel engine applications. Recent research highlighted the potential of pyrolysis oils as renewable biofuels for internal combustion (IC) engine applications [17, 18]. However, due to their low energy content, high acidity and viscosity, upgrade is required prior to use. One upgrade method is to blend pyrolysis oil with another component e.g. with biodiesel (or diesel) or other biofuels [19-24]. Among the various pyrolysis techniques, intermediate pyrolysis attracted attention due to the flexibility of the feedstock used (can process biomass with ash content as high as 30\%) [25-27]. Recent studies showed that intermediate pyrolysis oils 
potential fuel for diesel engine applications [28, 29]. Butanol acts as a good co-solvent for blending; stable single phase blends are produced when bio-oil, biodiesel and butanol are mixed [30]. Currently, butanol is being produced mainly from petrochemical resources; but bio-butanol can be produced from biomass resources via fermentation [31-33].

In a typical AD plant about $33-50 \%$ of the feedstock energy is converted into biogas [34, 35]. This means more than half of the feedstock energy remains in the digestate, making it a very promising feedstock for production of biofuel via, for example, the intermediate pyrolysis technique. Although researchers investigated the use of pyrolysis oils produced from various biomass resources, hardly any study was found on the use of digestate pyrolysis oil (DPO). The aim of the current study is to investigate the combustion and emission performance of digestate pyrolysis oil blends in a multi-cylinder indirect injection compression ignition engine. The objectives of the study were to: (i) produce and characterise intermediate pyrolysis oil from digestate, (ii) investigate and prepare stable pyrolysis oil blends, (iii) characterise pyrolysis oil blends, (iv) analyse combustion, performance and exhaust emissions characteristics of the pyrolysis oil blends used in the engine. In the present study, digestate pyrolysis oil was blended successfully with waste cooking oil (WCO) and butanol (BL) in various proportions. The physical and chemical properties of the digestate pyrolysis oil and blends were measured. The digestate pyrolysis oil blends were tested in a multi-cylinder indirect injection diesel engine. Engine combustion, performance and emission parameters were measured and analysed; these results were compared with the standard fossil diesel (FD) operation.

\section{Materials and Methods}

\subsection{Anaerobic Digestion and Digestate Pellets}

Anaerobic digestion produces two main products: digestate and biogas. The digestate used in this study comes from MeMon BV, a Dutch company, where the material from the anaerobic digestion of arable crops (maize and green rye) was dried and pelletised. The moisture content of the digestate was reduced from around $80 \%$ to $20 \%$ prior to pelletisation (digestate was dewatered in a centrifuge followed by drying in a rotary oven). The digestate was analysed in an accredited laboratory following the CEN standards for solid biofuels. The properties of the digestate pellets ( $6 \mathrm{~mm}$ diameter and $20 \mathrm{~mm}$ long) are shown in Table 1.

\subsubsection{Intermediate Pyrolysis of Digestate Pellets}

Digestate pellets were pyrolysed using a reactor known as the Pyroformer ${ }^{\circledR}$, an electrically heated auger pyrolysis reactor with two counter-rotating concentric screws (Fig. 1). The Pyroformer® used in this study can 
process high ash content materials at a feeding rate of up to $20 \mathrm{~kg} / \mathrm{h}$. The feedstock enters at one end of the reactor and is conveyed by the inner screw while releasing vapours and being converted into biochar (the solid residue in which ash remains). At the opposite end, fraction of the biochar exits the reactor; and the rest which moves from the inner to the outer screw is conveyed backwards to the feeding inlet side. Thus, the hot biochar mixes with the fresh feed material at the beginning of the inner screw; the biochar to biomass ratio in the inner screw is between 1 and 3 (on weight basis). The pyrolysis vapours (a mixture of condensable and permanent gases) pass through a trace heated pipe before entering into a shell and tube water heat exchanger (Fig. 1). Vapours are then routed into an electrostatic precipitator for aerosol removal, to a dry ice condenser $\left(\right.$ at $\left.0^{\circ} \mathrm{C}\right)$, two cotton filters, a volume meter, and finally flared using natural gas. Most of the liquid $(80 \%)$ is collected in the shell and tube heat exchanger and the rest in the electrostatic precipitator and in the dry ice condenser. The condensed liquid, collected in three bottles, is mixed and poured into separating funnels. As a result, the liquid separates into an organic phase (pyrolysis oil) and an aqueous phase (with $50 \%$ of light organics).

In this study, digestate pyrolysis oil was produced from digestate pellets feeding the Pyroformer ${ }^{\circledR}$ at feed rate of approximately $5 \mathrm{~kg} / \mathrm{h}$; and with a biochar to biomass ratio of three (inner and outer screw speeds were 6 and 4 rpm, respectively). The reactor electrical heater was set at $500^{\circ} \mathrm{C}$, and as a result vapours reached a temperature of about $390^{\circ} \mathrm{C}$. Once the steady state operation was reached, the products yields on weight basis were: $20 \%$ pyrolysis oil, $20 \%$ aqueous phase, $50 \%$ biochar and $10 \%$ of gas. The ash content of biochar was 60 $\%$, and higher heating value was $10 \mathrm{MJ} / \mathrm{kg}$.

\subsection{Characterisation and blends preparation}

\subsubsection{Characterisation of fuels}

The instruments used for measurement of various physical and chemical properties are: Canon Fenski u-tube viscometers (with measurement uncertainty of between $0.16 \%$ to $0.22 \%$ ) and a thermostatic water bath $\left( \pm 0.1^{\circ} \mathrm{C}\right)$ to measure the kinematic viscosities; densities were measured using a hydrometer according to ASTM-D7544; Parr 6100 bomb calorimeter was used to measure the higher heating values (HHV); flash point temperatures were measured using a Setaflash series 3 plus closed cup flash point tester (model 33000-0) according to ASTMD1655 standard. The measurement accuracies of the calorimeter and the flash point tester were $\pm 0.1 \%$ and \pm $0.5^{\circ} \mathrm{C}$. The lower heating value ( $\left.\mathrm{LHV}\right)$ was calculated from the HHV and the hydrogen content in the fuel. The water content was measured by Mettler Toledo V20 compact volumetric Karl-Fischer titration according to ASTME203 standard. The acid number was measured using a Mettler Toledo G20 compact titrator as per ASTM-66404. The readings were repeated three times to minimise errors and fluctuations. Corrosion tests were performed using a Stanhope-SETA cooper corrosion instrument as per ASTM D130 standard, with copper strips immersed 
127 into the fuel samples at $60^{\circ} \mathrm{C}$ (in a water bath) for 72 hours, and then matching their colour to the standard scale.

128 Moisture content (in digestate pellets), elemental analysis and ash content analysis were performed externally by 129 an accredited laboratory.

\subsubsection{Preparation of blends}

131 The physical and chemical properties of the pyrolysis oil were measured and compared with standard fossil diesel. The properties (shown in Table 2) would not permit use of the pure pyrolysis oil in an engine, primarily due to its low heating value, and high viscosity, acid number and corrosion rating. To investigate ways of improving the fuel value by blending, miscibility tests were carried out by mixing it separately with fossil diesel, biodiesel, soybean oil and waste cooking oil. Miscibility and stability were tested after manually stirring the liquids, and keeping the blends at room temperature during 30 days to see if any phase separation occurred. It was observed that the pyrolysis oil did not mix either with fossil diesel or biodiesel, but mixed with both soybean oil and waste cooking oil. Waste cooking oil (WCO) has lower commercial value than soybean oil and hence WCO was selected for blending with the pyrolysis oil. A third component, butanol (BL) was added to reduce the viscosity of the blends. Three blends were prepared (vol.): (i) 10\% DPO, 70\% WCO and 20\% BL, named as 10 DPO blend, (ii) $20 \%$ DPO, $60 \%$ WCO and $20 \%$ BL, named as 20 DPO blend, and (iii) $30 \%$ DPO, 50\% WCO and $20 \%$ BL, named as 30 DPO blend. Among these blends, 20 DPO and 30 DPO were used in the engine to test combustion, performance and exhaust emissions. These two DPO blends were filtered using $1 \mu \mathrm{m}$ sock filter before the engine testing, and no other additives or ignition improvers were used in the blends.

\subsection{Engine Tests}

147 A three cylinder Lister Petter Alpha series engine was used - the rated power of the engine is $9.9 \mathrm{~kW}$ at 1500 rpm. The combustion is an indirect injection type and the fuel supply system is through individual pumps and injectors into each cylinder - see Table 3. The engine test rig, including the various measurements is shown in Figure 2. A two-tank fuel supply system was adopted to switch from standard fuel to test fuels. The engine was operated at constant speed under variable load conditions. At first, the engine was tested with $100 \%$ FD and $100 \%$ WCO separately. After that the DPO blends (20\% and $30 \%$ blends) were used in the engine. Since the pyrolysis oil does not mix with the fossil diesel, the following operation strategy was applied to switch fuels: engine started with 100\% FD; switched to $100 \%$ WCO operation; switched to DPO blend operation; switched back to $100 \%$ WCO operation; switched back to $100 \%$ FD operation; stopped the engine. Measurements were recorded after approximately 20 minutes of switching fuel. Each operation lasted for about an hour. 


\subsubsection{Combustion Measurement}

160

Combustion analysis were performed using a system called 'KiBox To Go' developed by Kistler Instruments Ltd. The KiBox acquires the raw signals and it outputs the different key combustion analysis values in real time. The following sensors and instrumentations were used in the current study: a Kistler pressure sensor (Kistler 6125C11) and amplifier (Kistler 5064B11) were used to measure in-cylinder pressure; an optical encoder (Kistler 2614A) was used to detect crank angle position; another pressure sensor (Kistler 4065A500A0) and amplifier (Kistler 4618A0) were used to measure the fuel line injection pressure. Amplifiers convert the raw pressure signal into a precision-scaled voltage which forms the interface between sensor signal and measuring system. 'KiBoxCockpit' software was used to calculate the combustion parameters and provide the 'indicator diagram' that relates combustion chamber pressure to piston volume (or crank angle). The pressure curve (pressure crank angle cycle) represents the combustion i.e. the energy conversion inside the engine cylinder. The cylinder pressure, crank angle and engine geometry are the main parameters used by the software to calculate various combustion parameters. A total of 51 pressure traces were registered for each analysis. Standard deviation for in-cylinder pressures was in the range of 0.03 to 0.04 . Calculation and output of results include cylinder pressure analysis with respect to cylinder volume or crank angle, injection timing and pressure, ignition timing, energy release rates, integral energy, angular position of the energy transfer, knocking, mean rotational speed for each working cycle. Heat release rates calculations were performed using the first law of thermodynamics, P-V cycle, gas law and engine geometry. Thermodynamic calculation of the heat release was performed without taking into account the wall heat losses assuming closed cycle system with adiabatic compression and expansion. The start of combustion and combustion duration were derived from the derivatives of the heat release curve. Combustion analysis parameters were displayed and analysed in real-time.

\subsubsection{Engine Performance and Emission Measurement}

182 A Froude Hofmann AG80HS eddy current dynamometer was used to measure and control the engine load and

183 speed. Measurement accuracy for speed and torque are $\pm 1 \mathrm{rpm}$ and $\pm 0.4 \mathrm{Nm}$ respectively. An additional fuel filter was used, and to aid fuel flow the fuel tanks were placed at about 3m height. A Bosch BEA 850 five gas analyser and a Bosch RTM 430 smoke opacity meter (with a resolution of $0.1 \%$ ) were used to measure exhaust gas components and smoke intensity respectively. The resolution levels of various gases were: $\mathrm{CO}-0.001 \% \mathrm{vol}$., $\mathrm{CO}_{2}-0.01 \%$ vol., $\mathrm{HC}-1 \mathrm{ppm}, \mathrm{O}_{2}-0.01 \%$ vol. and $\mathrm{NO}_{x}-1 \mathrm{ppm}$. Fuel consumption for each test run was 
acquisition system were used to measure and log the temperatures at the various locations. In each case three readings were taken enabling repeatability of measurements.

\section{Results and Discussion}

In this section fuel properties and engine test results are presented. Properties of $100 \%$ DPO, $100 \%$ fossil diesel (FD), 100\% Butanol (BL), 100\% WCO and DPO blends (10 DPO, 20 DPO and 30 DPO) are discussed. Engine combustion, performance and exhaust emissions tests results are presented for 20 DPO and 30 DPO fuels. Multiple readings were taken in order to ensure the repeatability, and average values were used for analysis. The DPO blends tests results are compared with the FD operation.

\subsection{Characterisation of Pyrolysis oil and Blends}

The HHV (Higher Heating Value) and moisture content of the digestate pellets were $15.02 \mathrm{MJ} / \mathrm{kg}$ and 11.5\% (wt.) respectively (Table 1). The amount of volatile matter and carbon content (wt. \%, dry basis) in the pellets were $54.1 \%$ and $35.95 \%$ respectively (Table 1 ). The chlorine content in the digestate pellet is $0.87 \mathrm{wt}$ \% (Table 1 ). Chlorine content in the organic fraction (ie. DPO) was not measured in this study; literature reports that chlorine remains mainly in the non-condensable gas and in the biochar, with maximum $20 \%$ (wt.) staying in the liquid [36, 37] . Within the liquid, chlorine is dissolved as $\mathrm{HCl}$ in the aqueous phase, and only some of it reacts with organic compounds containing double bonds to remain in the organic phase [38]. Heavy metals were analysed in the digestate and biochar - showing that mercury, arsenic and selenium are below the detection limit of the analytical equipment (ICP-OES) (results not shown). Estimated results on the heavy metals content in the DPO blends were in the range of heavy metals found in the literature for biodiesel, except for manganese and zinc, which are much higher in the pyrolysis liquid, or in the 30DPO blend [39].

Viscosity values of the $100 \% \mathrm{DPO}$ at $40^{\circ} \mathrm{C}$ was approximately 158 times higher than that of FD (Table 2). Figure 3 shows that the viscosity values were decreased due to blending and also with the increase of temperature viscosity values (at $40^{\circ} \mathrm{C}$ ) of the DPO blends were only 5 to 7 times higher than that of FD. At room temperature, the viscosity of the 10 DPO blend is lower than 20 DPO (or 30 DPO) due to the lower content of DPO in the 10 DPO blend (Fig. 3). It was found that at high temperatures, viscosity values of the 20 DPO and 30 DPO blends were close to each other. Molecular breakdown of the DPO increases with the increase of temperature; hence, higher amount of DPO content in 20/30 DPO blends caused thinning of the blends quicker than that of 10 DPO blend. Multiple readings (at least three) were recorded for the same viscosity measurement, and standard deviation was in the range of 0.03 to 0.17 . The higher viscosity of the DPO blends would help to lubricate moving components in the engine such as fuel pumps, injectors and piston-cylinder; but on the other hand, this might 
222 incomplete combustion. The calorific values of the DPO blends were close to that of FD - for example, the HHV

223 value of 20 DPO blend was approximately $17 \%$ lower than the FD value. This is common in most biomass

224 derived fuels; higher oxygen content in DPO (Table 2) caused lower heating values. Flash point temperature is 225 important for transportation and storage of fuels. The flash point temperature of the $100 \%$ DPO was $20 \%$ lower 226 that of FD; on the other hand, flash point temperature of $100 \%$ WCO was approximately $65 \%$ higher than FD

227 value. The flash point temperatures of the DPO blends are in the range of $41^{\circ} \mathrm{C}$ to $44^{\circ} \mathrm{C}$. The ASTM copper 228 corrosion and acid number values of 20 DPO were $2 \mathrm{c}$ and 1.2 (wt. \%) respectively - the corresponding FD 229 values were $1 \mathrm{~b}$ and 0.023 (wt. \%). This indicates that acidity and copper corrosion scales of the DPO blends are slightly higher than corresponding FD values. Compared to FD, the density and water content of DPO and its blends were higher - for example, density of the 20 DPO fuel was $8 \%$ higher than FD. Density is an important property, as higher density would help to compensate engine power when lower heating value fuels are used. On the other hand, high density fuels might cause high injection pressure and high ignition delay. In addition, the higher the density, the lower will be the spray penetration length inside the pre-chamber. So, use of DPO blends might cause uneven combustion inside the cylinder and therefore can cause loss in engine brake power. Small amount of water present in the DPO blends might help to decrease the combustion temperature, the lower the combustion temperature the lower will be the NOx emission. On the other hand, nitrogen content in the 20 DPO blend was higher than FD (Table 2); high nitrogen content would generally lead to high NOx emission. Sulphur content levels both in the 100\% DPO and 100\% FD were at trace levels. Carbon and hydrogen content in the 20 DPO blend were close to that of FD (Table 2). The oxygen content in DPO blend (and pure DPO) is higher than diesel (Table 2). High oxygen content would help to combust access DPO blends which would need to supply to compensate the engine power loss due to the low heating value and high viscosity properties of the DPO blends.

\subsection{Engine Combustion Parameters Analysis}

245 The in-cylinder pressures results showed that in almost all load conditions, the DPO blends produced slightly 246 uneven pressure profile compared to pure FD or WCO operation (Fig. 4a and 4b) - it was thought that the high ignition delay and uneven combustion of the DPO blends caused this behaviour. The compounds present in the pyrolysis oil contain wide range of boiling points from 60 to $340^{\circ} \mathrm{C}$ [27]. Low cetane number [19, 27], high density and viscosity values, and complex compound characteristics of the DPO blends caused high ignition delay and uneven combustion of the DPO blends. In general, for all fuels, the peak in-cylinder pressure increased with the increase of engine load; but it was observed that the DPO blends peak in-cylinder pressures were lower than FD and WCO operation (Fig. 4c). Compared to FD and at $80 \%$ engine load operation, the peak in-cylinder pressures 
of the 20 DPO and 30 DPO blends were decreased by $2 \%$ and $4 \%$ respectively. It was thought that uneven combustion of the DPO blends caused this. Crank angle positions at peak cylinder pressures didn't change considerably for all load operation (Fig. 4d).

In the case of high engine loads, heat energy released by the DPO blends was almost similar to that of FD and WCO operation (Fig. 5) - which indicated that at high combustion temperature DPO blends combusted well. For all fuels, integral heat release was increased with the increase of the engine loads (Fig. 5) as more fuel needs to be combusted to get higher engine output. For both DPO blends, the maximum heat release rate was approximately $8 \%$ higher than FD (and WCO) operation (Fig. 5d). In addition, integral heat release curves showed that for all fuels most burning took place within about $20^{\circ} \mathrm{CA}$ after TDC at low engine loads and within about $30^{\circ} \mathrm{CA}$ after TDC at high engine loads - i.e. higher the engine load higher is the combustion duration (Fig. 5). Differences in the integral heat release values of the DPO blends and FD were observed after this position (20 to $30^{\circ} \mathrm{CA}$ ) due to the variations in the total combustion - for example, at $40 \%$ engine load, DPO heat release values were lower than FD due to the poor combustion of DPO at low temperature; on the other hand, at 100\% load, heat release values are higher than that of FD due to the better combustion of DPO at high temperature (Fig. 5). The combustion of DPO blends operation was not smooth (Figure 6) - high viscosity and multiple components present in the pyrolysis oil caused this behaviour. It was believed that some components of the DPO blends combusted early and other combusted late and eventually led to uneven combustion (Fig. 6). Figure 7 shows the start of combustion and combustion duration of various fuels under different load conditions. It was observed that for all fuels, both combustion and heat release duration were increased with the increase of engine loads (Fig. 6 and 7) - i.e. higher the energy released higher is the engine output. Furthermore, for the same engine power output the area under the heat release curve were bigger in the case of DPO blends when compared with the FD - i.e. higher amount of DPO fuels combusted to produce same output power (Fig. 6). It was observed that, in general, the start of combustion was delayed in the case of DPO blends compared to FD (and WCO) (Fig. 7a) - the low cetane number of the DPO blends delayed start of combustion. In most load conditions, combustion of the DPO blends fuels finished earlier than that of FD (Fig. 7c) - this behaviour can be explained as 'pyrolysis oil blends started to combust late, and in most load conditions once combustion started burnt quicker than FD'. This characteristic of DPO blends combustion caused decreased total combustion duration than FD or WCO operation (Fig. 7d). Results showed that total combustion duration for 30DPO is higher than 20 DPO in the case of low engine loads; whereas, this is either similar or lower than 20DPO fuel in the case of high engine loads (Fig. 7d). It was thought that better combustion of DPO blends at high engine loads caused this behaviour. Compared to FD operation and at $100 \%$ load, the total burning duration of the 20 DPO and 30 DPO blends were decreased by approximately $12 \%$ and $3 \%$ respectively. It was observed 

viscosity and density values of the DPO blends and WCO fuels (Figure not shown).

\subsection{Engine Performance and Exhaust Emissions Analysis}

\subsubsection{Engine Performance}

290

Full engine power was achieved with the DPO blends; engine performance parameters were measured and compared with FD and WCO operation. The brake specific fuel consumption (BSFC) results were compared (Fig. 8a) - DPO blends have lower heating values than FD, so the engine consumed a higher amount fuel to deliver the same power. The differences in fuel consumption were lower if compared on volume basis rather than weight basis due to the higher density values of DPO blends than FD (Table 2) - at full engine load, the BSFC of the 30 DPO blend and 20 DPO were approximately 19\% and 5\% higher than FD (Figure not shown). On the other hand, the BSFC of the 30 DPO blend and 20 DPO were approximately $32 \%$ and $15 \%$ higher than FD on weight basis (Fig. 8a). At low loads, both 20 DPO and FD fuels gave almost similar thermal efficiency (Fig. 8b). Whereas, compared to FD and at full load, the brake thermal efficiencies of the DPO blends were decreased by $7 \%$ and $3 \%$ respectively for 30 DPO and 20 DPO operations (Fig. 8b). To compensate the slight power loss due to the uneven combustion of the DPO blends, the engine consumed higher amount of fuels and hence gave lower thermal efficiency as compared to FD operation. The exhaust temperature is important for combined heat and power application. It was observed that the exhaust gas temperatures were almost similar for all fuels; however, at full engine load, the exhaust gas temperature of the 30 DPO fuel was $6 \%$ lower than that of FD (Fig. 8c). The DPO blends produced lower smoke levels than FD - at full engine load, smoke level of 20 DPO fuel was approximately $44 \%$ lower than corresponding FD smoke (Fig. 8d). On the other hand, DPO blend smoke was higher than FD in low load operation. Higher oxygen content in the DPO blends (Table 2) helped combustion of the DPO blends and hence generated lower smoke than FD.

\subsubsection{Exhaust Gas Emissions}

Analyses of the greenhouse gas (GHG) emissions are important to assess the scale of atmospheric pollution when any new fuel is used in the engine. The GHG emissions produced by the DPO blends were compared with the reference emissions produced by FD. No significant differences were observed in the $\mathrm{CO}_{2}$ gas emissions - at

312 full engine load the 30 DPO fuel produced $5 \%$ higher $\mathrm{CO}_{2}$ emission than FD (Fig. 9a). Higher DPO blends 313 consumption (section 3.3.1) at full load caused higher $\mathrm{CO}_{2}$ emissions. Figure $9 \mathrm{~b}$ shows $\mathrm{CO}$ emission of all fuels at various loads. Compared to FD, DPO blends produced higher CO emission at low load, and lower CO emission at high engine loads. At full load, CO emission of the 20 DPO blend was decreased by $39 \%$ than FD; 
higher oxygen content in the DPO blends might have caused this (Table 2). In addition, lower CO emission also

317 helped to emit low level of smoke at high load condition (Fig 8 and 9). At low load, the viscosities of the DPO blends are relatively higher and hence produced poor atomisation of fuels inside the engine cylinder. The poor quality spray of the DPO blends produced higher $\mathrm{CO}$ emissions at low load operation. No major differences in the $\mathrm{O}_{2}$ emissions were observed (Figure not shown) - high oxygen content in the DPO and WCO fuels helped to combust excess amount of fuels in order to produce the same engine power output. At low load, the NOx emission of the DPO blends were lower than FD; but on the other hand, at high engine loads the opposite relation was observed (Fig. 9c). Higher density values (Table 2) and lower smoke levels (Fig. 8) of the DPO blends might have caused higher $\mathrm{NO}_{x}$ emission in the case of DPO blends operation at higher engine loads. At low load condition, the smoke level was higher and hence lower NOx was produced in the case of DPO blends as compared to FD.

\section{Conclusions}

Pyrolysis oil produced from AD digestate in various blends with butanol and waste cooking oil proved to be a suitable engine fuel in the scope of the tests described here, and shows promise as a potential biofuel source for both $\mathrm{CHP}$ and transport engine applications. However, long term engine testing will be required to assess the durability of the fuel systems and engine components. In Europe, AD plants are increasingly used. The use of AD digestate as renewable biofuel would help EU to reduce the GHG emissions, to increase the share of renewables and to meet the energy efficiency targets. This would also help to manage AD waste (digestate) in a more sustainable way.

\section{Specific conclusions: blending and characterisation}

337 (i) Stable fuel blends were produced by mixing digestate pyrolysis oil with waste cooking oil and butanol.

338 (ii) Compared to FD, kinematic viscosities (at $40^{\circ} \mathrm{C}$ ) of the DPO blends were 5 to 7 times higher; and HHV 339 value of 20 DPO blend was approximately $17 \%$ lower. The ASTM copper corrosion values of 20 DPO and 30 DPO blends were 2c which indicates suitability for use in internal combustion engines.

(iii) Pyrolysis oil blends (20 DPO and 30 DPO) were tested successfully in a 9.9 kW indirect injection multicylinder engine. No ignition improver or surfactant was added in the blend. 
(iv) DPO blends produced slightly uneven in-cylinder pressure profiles compared to both FD and WCO. At $80 \%$ load operation, combustion of 20 DPO and 30 DPO fuels caused lower peak cylinder pressures by $2 \%$ and $4 \%$ respectively compared with FD.

(v) The maximum heat release rates of both DPO blends were approximately $8 \%$ higher than for FD and

(vi) Compared to FD, the BSFC of the 30 DPO and 20 DPO fuels were approximately $19 \%$ and $5 \%$ higher on volume basis, and approximately $32 \%$ and $15 \%$ higher on weight basis.

(vii) At full load, the brake thermal efficiency of the DPO blends were decreased by $7 \%$ and $3 \%$ respectively when 30 DPO and 20 DPO blends were used. DPO blends gave lower smoke levels than FD - at full engine load, smoke level of the 20 DPO fuel was approximately 44\% lower than corresponding FD smoke.

(viii) Almost similar $\mathrm{CO}_{2}$ gas emissions were recorded from both DPO blends and FD fuels - at full engine load, for 30 DPO blend produced 5\% higher $\mathrm{CO}_{2}$ emission than FD. At full load, the $\mathrm{CO}$ emission of the 20 DPO

(ix) Further studies on the pyrolysis of AD digestate from various biomass feedstocks are needed to assess

(x) Use of non-edible plant oil instead of waste cooking oil would help to increase the flash point temperature and hence promote better combustion of the DPO blends in the engine.

(xi) High viscosity and low heating values of the DPO prevented higher amounts of DPO from being used in

(xii) Comparing the DPO blends exhaust gas emissions with respect to Euro VI requirements are recommended. direct injection engine is another area of further investigation. 
The research leading to these results has received funding from the European Union's Seventh Framework

Programme [FP7/2007-2013] under grant agreement no. 286244. The authors would like to thank MeMon BV for supplying the digestate feedstock. The authors also acknowledge Mr Muhammad Saghir for providing technical assistance and advice.

\section{References}

1. EU. Climate Action - EU greenhouse gas emissions and targets. 2014; Available from:

http://ec.europa.eu/clima/policies/g-gas/index en.htm.

2. EU. 2030 framework for climate and energy policies. 2014; Available from:

3. http://ec.europa.eu/clima/news/articles/news 2014102801

4. Växtkraft - Process description of the Biogas plant in Västerås. 2006.

5. Kocar, G., The use of anaerobically digested slurry combined with natural zeolite for rapeseed production. Energy Education Science and Technology Part A: Energy Science and Research, 2012. 30(1): p. 545 - 552.

6. UNEP Global Programme of Action, Guidance on Municipal Wastewater,

7. W. Kossmann, U.P., S. Habermehl, T. Hoerz, P. Krmer, B. Klingler, C. Kellner, T. Wittur, F. v. Klopotek, A. Krieg, H. Euler, Biogas Digest, Volume II, Biogas-Application and Product Development. 1999.

8. LUKEHURST, C.T., FROST, P., SEAD, T. A., IEA Bioenrgy Task 37- Utilisation of digestate from biogas plants as biofertiliser. 2010.

9. Hailong Li, J.L., Eva Nordlander, Eva Thorin, Erik Dahlquist, Li Zhao, Using the Solid Digestate from a Wet Anaerobic Digestion Process as an Energy Resource. Energy Technology, 2013. 1: p. 94 - 101.

10. Daegi Kim, K.L., Ki Young Park, Hydrothermal carbonization of anaerobically digested sludge for solid fuel production and energy recovery. Fuel, 2014. 130: p. 120 - 125.

11. Murakami, T., et al., Combustion characteristics of sewage sludge in an incineration plant for energy recovery. Fuel Processing Technology, 2009. 90(6): p. 778-783.

12. Rigby, H., Smith, S. R., New Markets for Digestate from Anaerobic Digestion. 2011.

13. Rulkens, W., Sewage Sludge as a Biomass Resource for the Production of Energy: Overview and Assessment of the Various Optionst. Energy \& Fuels, 2007. 22(1): p. 9-15.

14. Shane M. Troy, T.N., James J. Leahy, Peadar G. Lawlor, Mark G. Healy, and W. Kwapinski, Effect of sawdust addition and composting of feedstock on renewable energy and biochar production from pyrolysis of anaerobically digested pig manure. Biomass and Bioenergy, 2013. 49: p. 1-9.

15. Werther, J. and T. Ogada, Sewage sludge combustion. Progress in Energy and Combustion Science, 1999. 25(1): p. 55-116.

16. Yue, Z., et al., A sustainable pathway of cellulosic ethanol production integrating anaerobic digestion with biorefining. Biotechnology and Bioengineering, 2010. 105(6): p. 1031-1039.

17. Barth, T., Kleinert, M., Motor fuels from biomass pyrolysis. Chemical Engineering \& Technology, 2008. 31(5): p. 773-781.

18. Jones, S.B., Holladay, J. E.,Valkenburg,C., Stevens, D. J., Walton, C. W., Kinchin, C. et al., Production of gasoline and diesel from biomass via fast pyrolysis, hydro-treating and hydrocracking: a design case. 2009, US Department of Energy,Pacific Northwest NationalLaboratory. 
19. Hossain, A.K., Davies, P. A., Pyrolysis liquids and gases as alternative fuels in internal combustion engines $-A$ review. Renewable and Sustainable Energy Reviews, 2013. 21(0): p. 165-189.

20. Zhang, $\mathrm{H}$. and J. Wang, Combustion characteristics of a diesel engine operated with diesel and burning oil of biomass. Renewable Energy, 2006. 31(7): p. 1025-1032.

21. Murugan, S., M.C. Ramaswamy, and G. Nagarajan, Assessment of pyrolysis oil as an energy source for diesel engines. Fuel Processing Technology, 2009. 90(1): p. 67-74.

22. Murugan, S., M.C. Ramaswamy, and G. Nagarajan, The use of tyre pyrolysis oil in diesel engines. Waste Management, 2008. 28(12): p. 2743-2749.

23. Martínez, J.D., et al., Potential for using a tire pyrolysis liquid-diesel fuel blend in a light duty engine under transient operation. Applied Energy, 2014. 130: p. 437-446.

24. Honnery, D., J. Ghojel, and V. Stamatov, Performance of a DI diesel engine fuelled by blends of diesel and kiln-produced pyroligneous tar. Biomass and Bioenergy, 2008. 32(4): p. 358365.

25. Hornung, A., A. Apfelbacher, and S. Sagi, Intermediate pyrolysis: A sustainable biomass-toenergy concept-biothermal valorisation of biomass (BtVB) process. Journal of Scientific and Industrial Research, 2011. 70(8): p. 664-667.

26. Yang, Y., et al., Intermediate pyrolysis of biomass energy pellets for producing sustainable liquid, gaseous and solid fuels. Bioresource Technology, 2014. 169(0): p. 794-799.

27. Yang, Y., et al., Characterisation of waste derived intermediate pyrolysis oils for use as diesel engine fuels. Fuel, 2013. 103(0): p. 247-257.

28. Hossain, A.K., et al., Experimental investigation of performance, emission and combustion characteristics of an indirect injection multi-cylinder $\mathrm{Cl}$ engine fuelled by blends of de-inking sludge pyrolysis oil with biodiesel. Fuel, 2013. 105(0): p. 135-142.

29. Yang, Y., et al., Investigation into the performance and emissions of a stationary diesel engine fuelled by sewage sludge intermediate pyrolysis oil and biodiesel blends. Energy, 2013. 62(0): p. 269-276.

30. Alcala, A. and A.V. Bridgwater, Upgrading fast pyrolysis liquids: Blends of biodiesel and pyrolysis oil. Fuel, 2013. 109(0): p. 417-426.

31. Gallego, L.J., et al., King Grass: A promising material for the production of second-generation butanol. Fuel, 2015. 143(0): p. 399-403.

32. Kheyrandish, M., et al., Direct production of acetone-butanol-ethanol from waste starch by free and immobilized Clostridium acetobutylicum. Fuel, 2015. 142(0): p. 129-133.

33. US Department of Energy. Alternative Fuels Data Centre - Biobutanol. Available from: http://www.afdc.energy.gov/fuels/emerging biobutanol.html.

34. Hossain, A.K., A model for sustainable biomass electricity generation in Bangladesh. 2005, Cranfield University: UK.

35. Sørensen, B., Renewable Energy - Physics, Engineering, Environmental Impacts, Economics and Planning. 4th ed. 2011: Elsevier.

36. Du, S., Wang, X., Shao, J., Yang, H., Xu, G., Chen, H., Releasing behavior of chlorine and fluorine during agricultural waste pyrolysis. Energy, 2014. 74: p. 295-300.

37. Bhaskar, T., Tanabe, M., Muto, A., Sakata, Y., Liu, C., Chen, M., Chao, C., Analysis of chlorine distribution in the pyrolysis products of poly(vinylidene chloride) mixed with polyethylene, polypropylene or polystyrene. Polymer Degradation and Stability, 2005. 89(1): p. 38-52.

38. Koo, W., Jung, S., Kim, J., Production of bio-oil with low contents of copper and chlorine by fast pyrolysis of alkaline copper quaternary-treated wood in a fluidized bed reactor. Energy, 2014. 68: p. 555-561.

39. Wang, Y., Huang, K., Li, C., Mi, H., Luo, J., Tsai, P., Emissions of fuel metals content from a diesel vehicle engine. Atmospheric Environment, 2003. 37(33): p. 4637-4643. 
Proximate analysis

Moisture content (wt. \%)

11.5

Ash content (wt. \%, dry basis)

35.7

Volatile matter (wt. \%, dry basis)

Proximate analysis (wt. \%, dry basis)

Carbon

Hydrogen

Nitrogen

3.54

Chlorine

0.87

High Heating Value (MJ/kg)

15.02

475

476

477

478

479

480

481

482

483

484

485

486

487

488

489

490

491 
Physical and chemical properties of the digestate pyrolysis oil (DPO), waste cooking oil (WCO), fossil diesel (FD), butanol (BL) and DPO blends

\begin{tabular}{|c|c|c|c|c|c|c|c|c|c|c|c|c|c|}
\hline $\begin{array}{l}\text { Density } \\
\left(\mathrm{kg} / \mathrm{m}^{3}\right)\end{array}$ & $\begin{array}{l}\text { Calorific } \\
\text { Value } \\
\mathrm{MJ} / / \mathrm{kg} \\
\mathrm{HHV}\end{array}$ & $\begin{array}{l}\text { Calorific } \\
\text { Value } \\
\text { MJ//kg } \\
\text { LHV }\end{array}$ & $\begin{array}{l}\text { Flash } \\
\text { Point } \\
\left({ }^{\circ} \mathrm{C}\right)\end{array}$ & $\begin{array}{l}\text { Kinematic } \\
\text { viscosity } \\
@ 20^{\circ} \mathrm{C} \\
\text { (cSt) }\end{array}$ & $\begin{array}{l}\text { Kinematic } \\
\text { viscosity } \\
@ 40^{\circ} \mathrm{C} \\
\text { (cSt) }\end{array}$ & $\begin{array}{l}\text { Kinematic } \\
\text { viscosity } \\
@ 60^{\circ} \mathrm{C} \\
\text { (cSt) }\end{array}$ & $\begin{array}{l}\text { Kinematic } \\
\text { viscosity } \\
@ 80^{\circ} \mathrm{C} \\
\text { (cSt) }\end{array}$ & $\begin{array}{l}\text { Water } \\
\text { content } \\
\text { (wt. \%) }\end{array}$ & $\begin{array}{l}\text { Acid } \\
\text { number } \\
\mathrm{KOH} / \mathrm{g}\end{array}$ & $\begin{array}{l}\text { ASTM Copper } \\
\text { corrosion } \\
\text { rating @ } 60^{\circ} \mathrm{C} \\
\text { for } 72 \text { hours }\end{array}$ & $\begin{array}{l}\text { C content } \\
\text { (wt. \%) }\end{array}$ & $\begin{array}{l}\text { H content } \\
\text { (wt. \%) }\end{array}$ & $\begin{array}{l}\mathrm{N} \text { conten } \\
\text { (wt. \%) }\end{array}$ \\
\hline 1077.14 & 26.77 & 25.01 & 54.00 & - & 473.99 & 129.82 & 50.55 & 6.40 & 8.4 & $3 a$ & 68.00 & 8.30 & 6.50 \\
\hline 910.00 & 39.83 & 38.22 & 112.67 & 62.34 & 28.54 & 16.29 & 10.25 & 0.19 & 0.7 & $1 b$ & 62.90 & 7.60 & 4.50 \\
\hline 835.00 & 45.30 & 42.50 & 68.00 & 3.22 & 3.01 & 1.91 & 1.37 & 0.06 & 0.02 & $1 b$ & 84.00 & 13.20 & $<0.10$ \\
\hline 810.00 & 35.45 & 32.48 & 35.00 & 0.80 & - & - & - & - & - & - & 65.00 & 14.00 & - \\
\hline 891.00 & 37.56 & - & 43.50 & 30.48 & 17.42 & 9.63 & 5.91 & - & - & - & - & - & - \\
\hline 903.67 & 37.45 & 35.07 & 42.00 & 43.82 & 20.27 & 10.99 & 6.99 & 1.80 & 0.9 & $2 c$ & 73.70 & 11.20 & 0.55 \\
\hline 921.40 & 34.41 & - & 41.00 & 47.56 & 20.75 & 11.26 & 7.10 & 2.70 & 1.2 & $2 c$ & - & - & - \\
\hline
\end{tabular}


Compression ignition engine and fuel system specification

\begin{tabular}{ll}
\hline Model & Alpha Series LPWS Bio3 \\
No of cylinders & 3 \\
Bore & $86 \mathrm{~mm}$ \\
Stroke & $80 \mathrm{~mm}$ \\
Cylinder volume & 1.395 litres \\
Manufacturer & Lister Petter, UK \\
Aspiration & Natural \\
Minimum full load speed & $1500 \mathrm{rpm}$ \\
Continuous power & $9.9 \mathrm{~kW}$ at $1500 \mathrm{rpm}$ \\
Compression ratio & 22 \\
Fuel consumption at rated load & Fossil diesel - 3.19 litres/hr \\
Glow plugs & Combustion-chamber glow plugs \\
Injection system & Indirect injection, individual injector \\
Injection timing & and fuel pump \\
Jacket water flow rate at rated power & $20^{\circ} \mathrm{CA}$ BTDC \\
Exhaust gas flow at rated power & 33 litres/min \\
Maximum permissible intake restriction at & 41.4 litres/sec \\
continuous power & 25 mbar \\
Maximum permissible exhaust & 75 mbar \\
backpressure at continuous power & 1 bar \\
Lubricating oil pressure at idle & \\
\hline
\end{tabular}

Table 3 


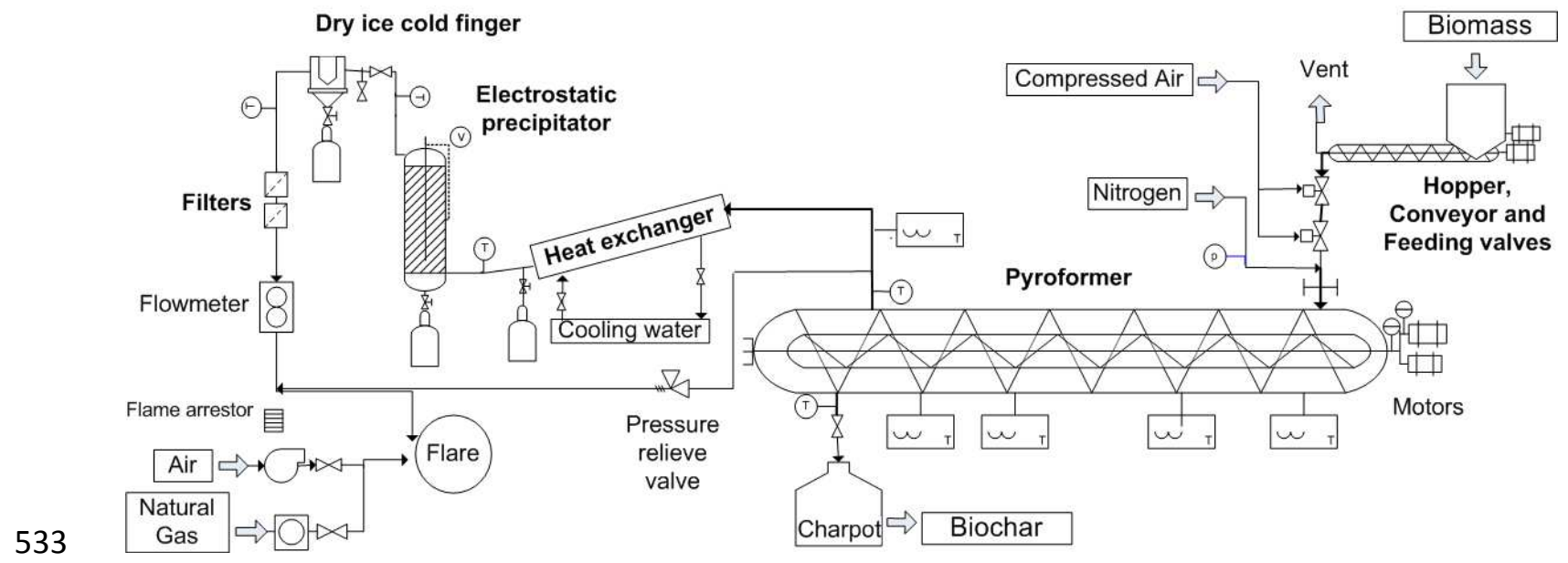

534

535

536

Figure 1 - Intermediate Pyrolysis (Pyroformer $\left.{ }^{\circledR}\right)$ - reactor and accessories

537

538

539

540

541

542

543

544

545

546

547

548

549

550

551

552

553

554 


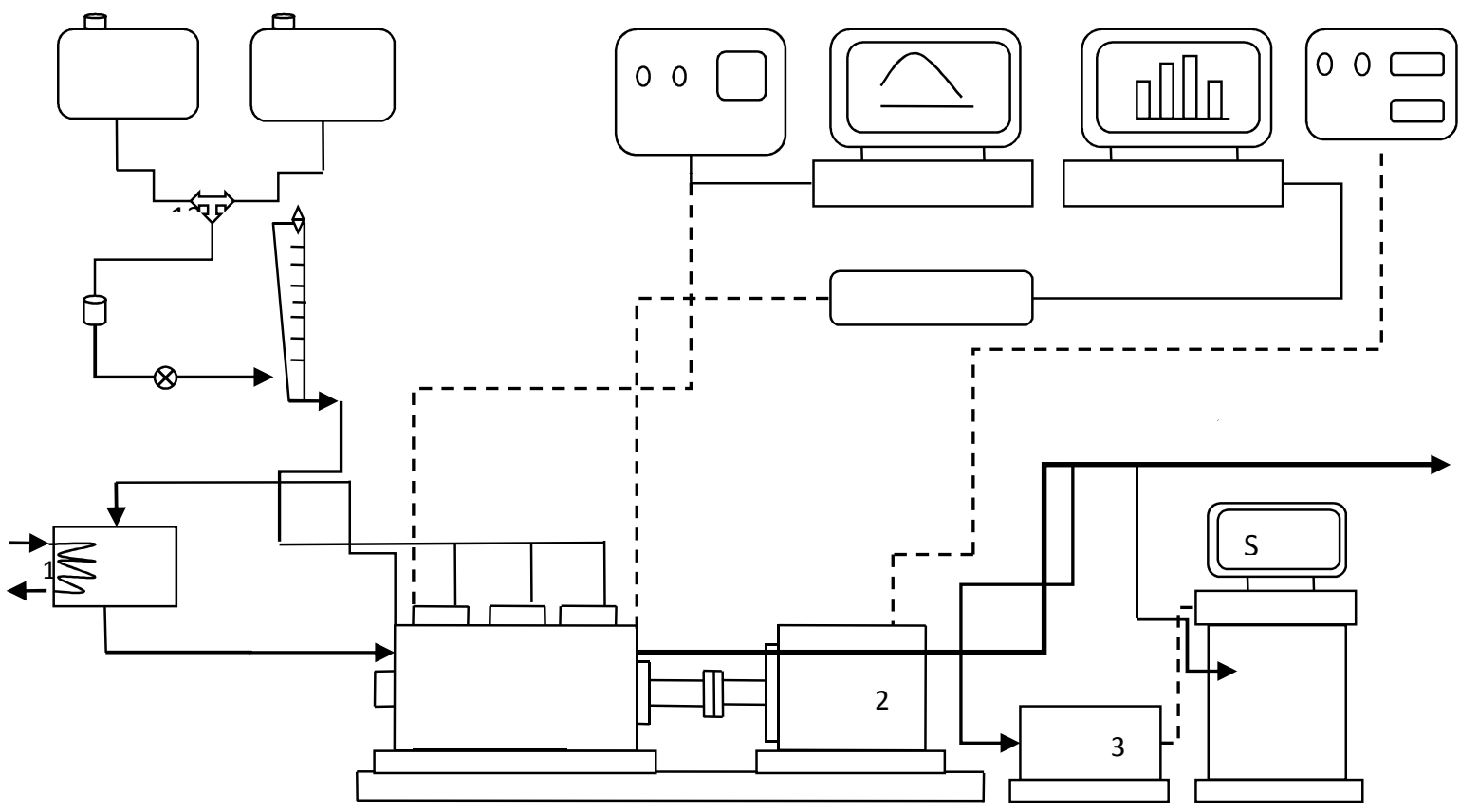

1: Engine; 2: Dynamometer; 3: Smoke meter; 4: Exhaust gas analyser; 5: Exhaust gas and smoke data acquisition; 6: Exhaust gas discharge; 7: Dynamometer controller; 8: NI data acquisition for temperature; 9, 10: Kistler combustion analyser; 11: DPO blend tank; 12: Diesel/WCO tank; 13: 3-way valve; 14: Vent screw; 15: Additional fuel filter; 16: Open/close valve; 17: Fuel measurement; 18: Cold water flow to HX; 19: HX to cool jacket water; 20: NI DAQ 


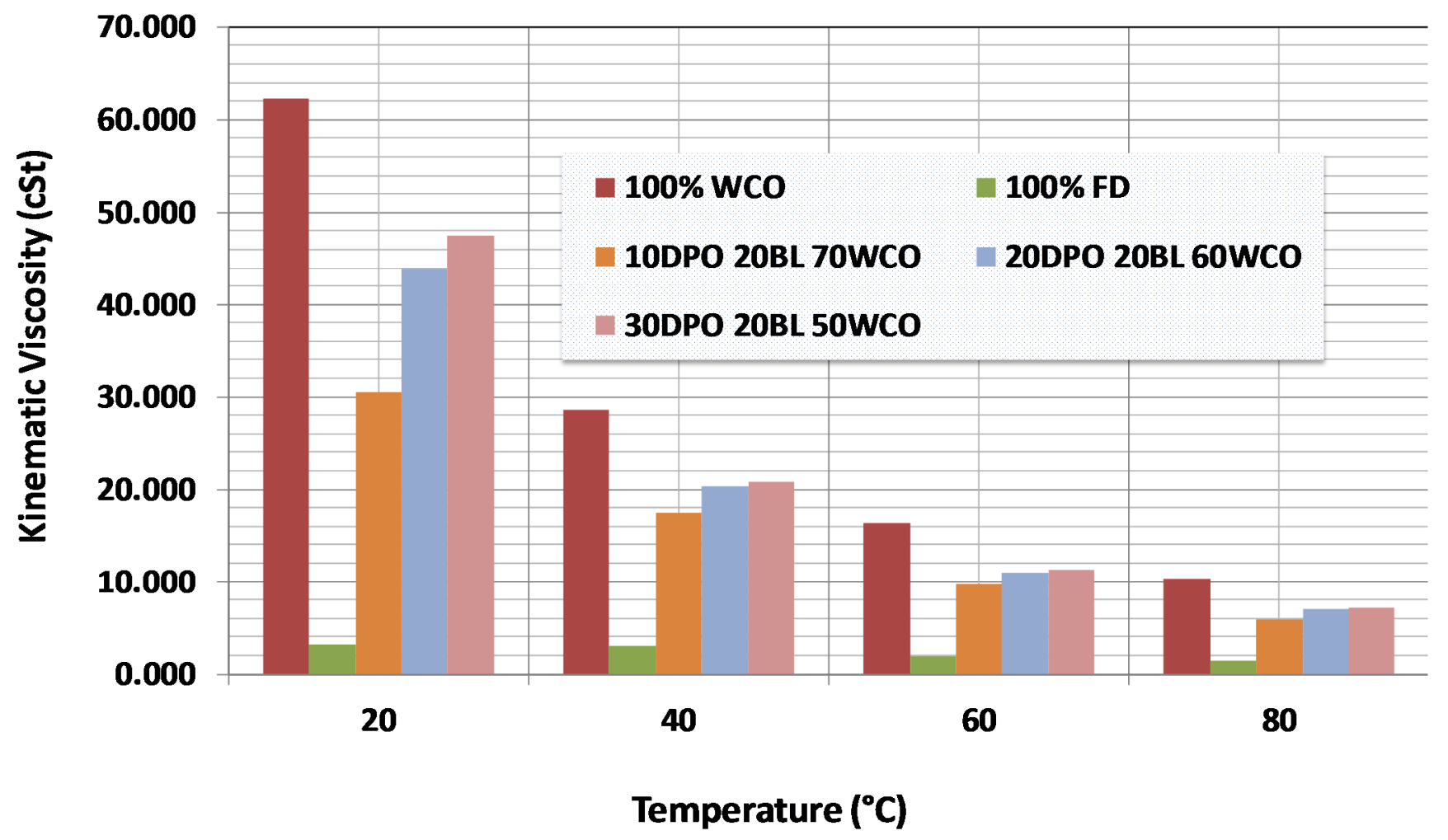




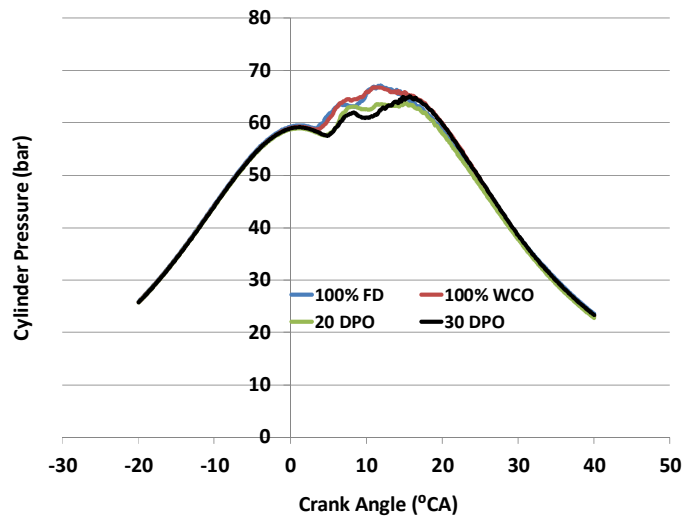

(a) in-cylinder pressure at $70 \%$ engine load

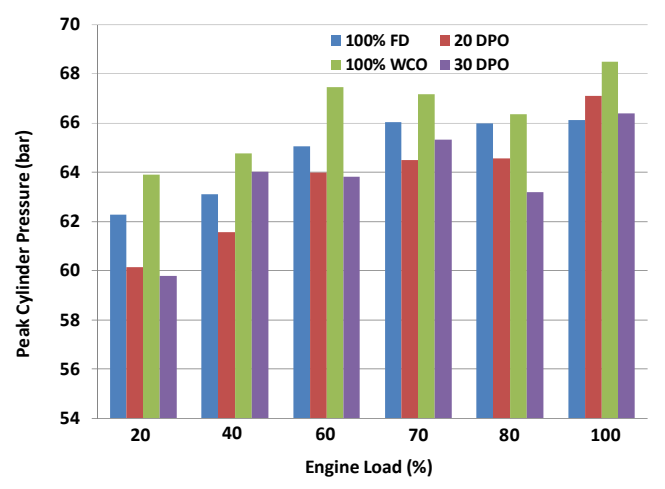

(c) maximum In-cylinder pressure vs. engine load

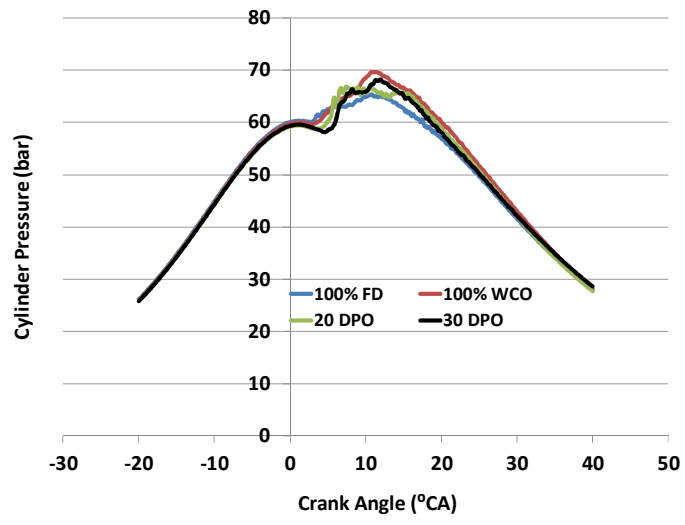

(b) in-cylinder pressure at $100 \%$ engine load

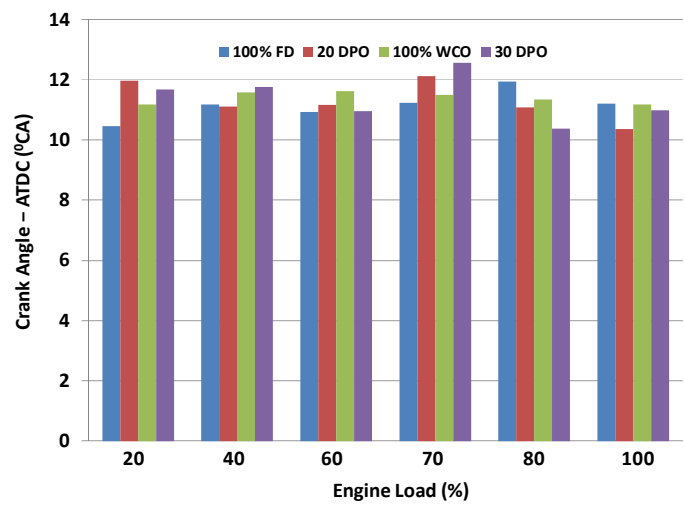

(d) crank angle position vs. engine load (at maximum in-cylinder pressure)

Figure 4 - Results showing in-cylinder pressures (and peak pressures) of the DPO blends with 


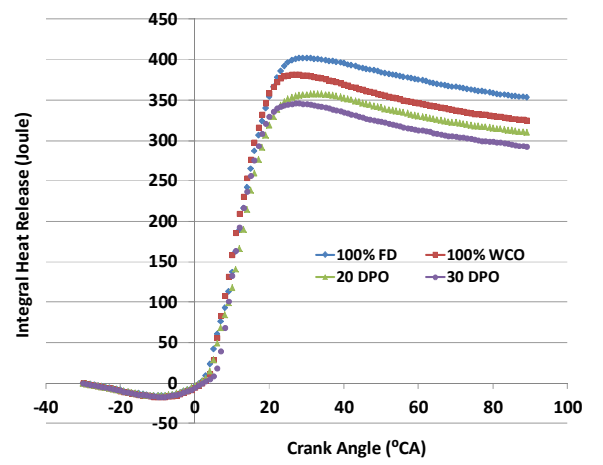

(a) integral heat release at $40 \%$ engine load

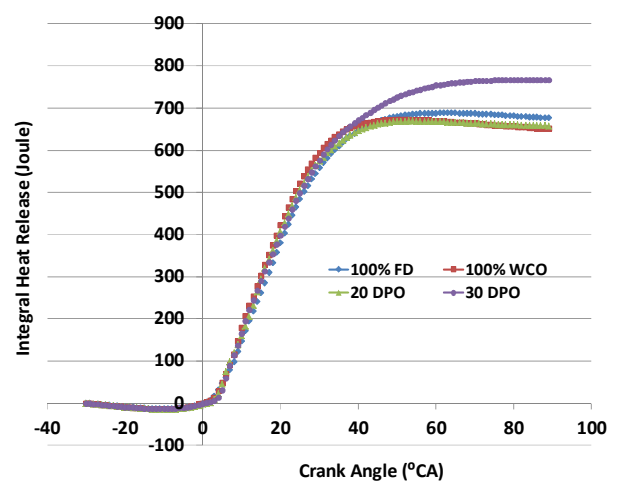

(c) integral heat release at $100 \%$ engine load

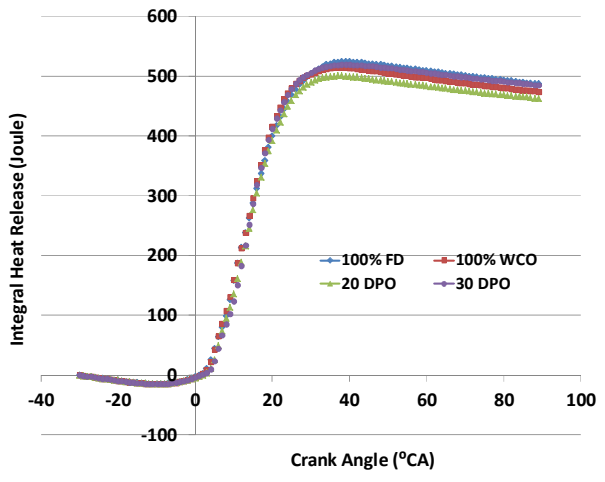

(b) integral heat release at $70 \%$ engine load

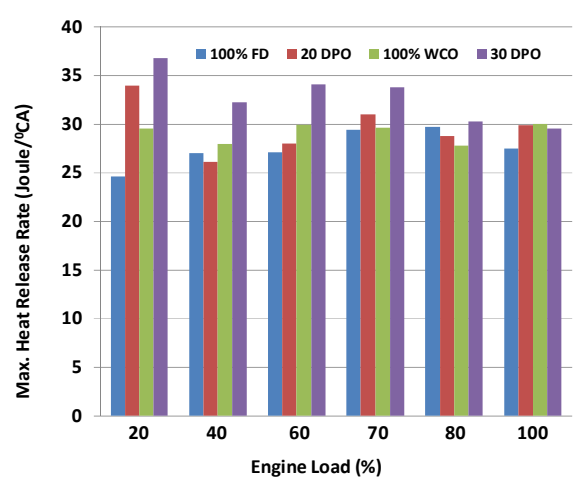

(d) maximum heat release rates as a function of load 


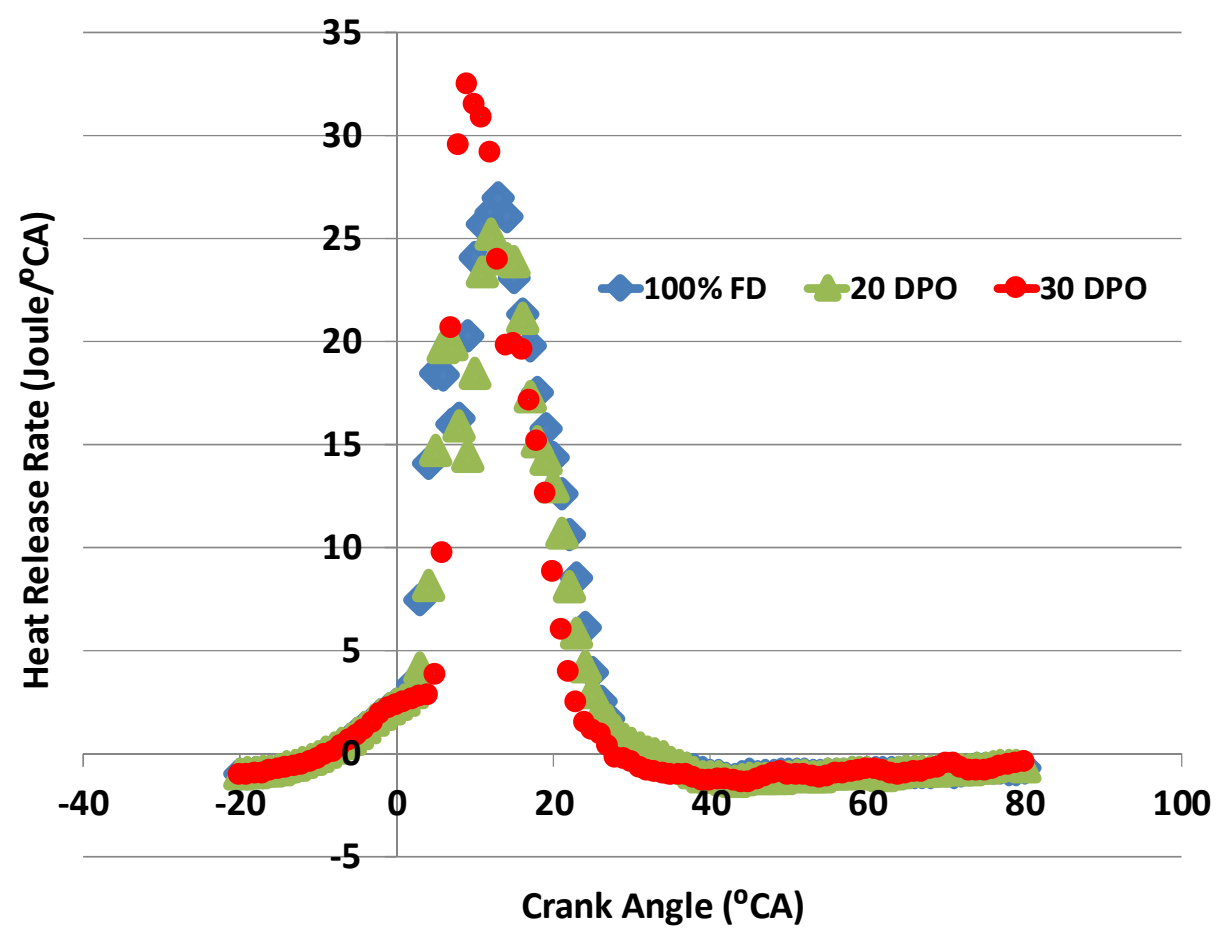

(a) at $40 \%$ engine load

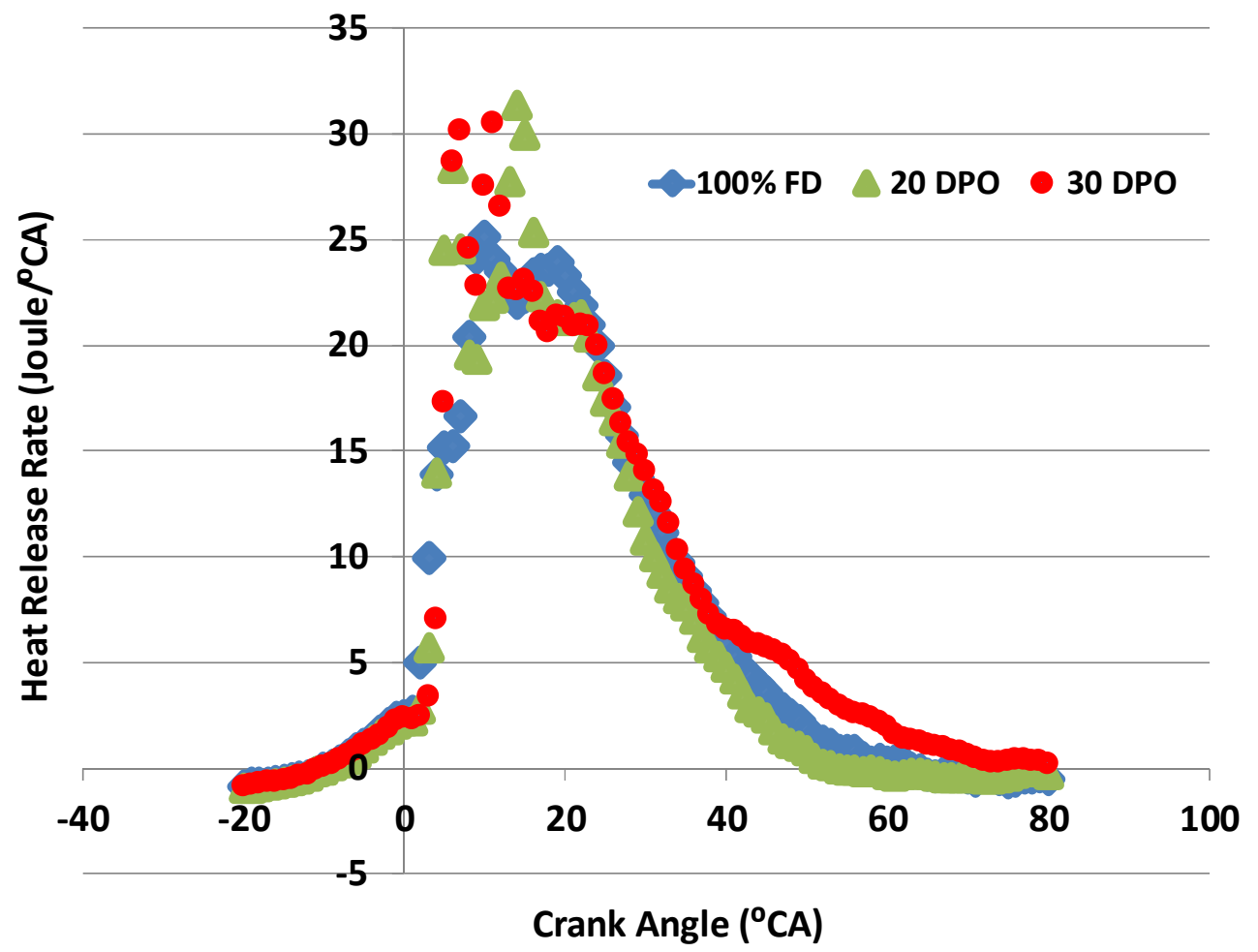

(b) at $100 \%$ engine load

Figure 6 - Distribution of the heat release rates of DPO blends and FD fuels at different loads 


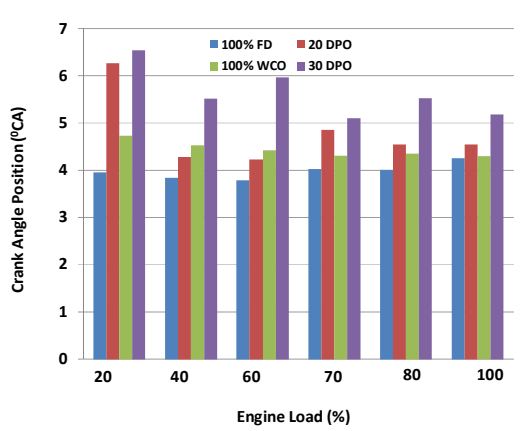

(a) crank angle position at $5 \%$ combustion

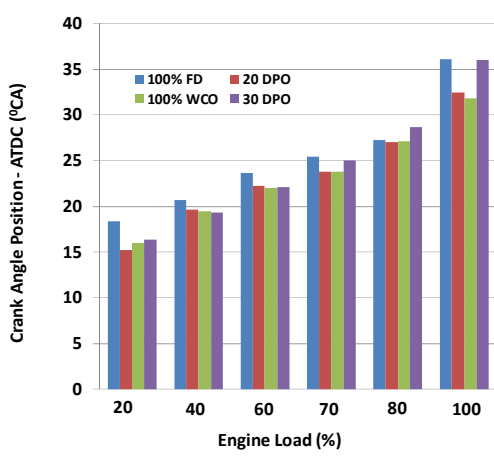

(c) crank angle position at $90 \%$ combustion

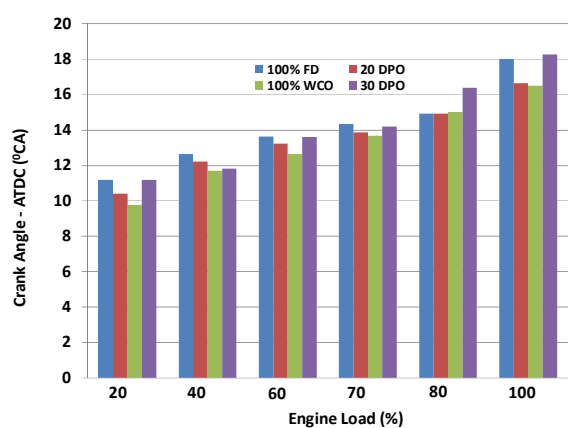

(b) crank angle position at $50 \%$ combustion

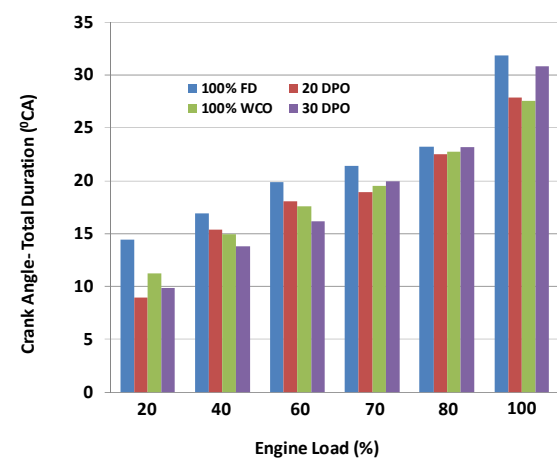

(d) total combustion duration

Figure 7 - Results showing the crank angle positions at various stages of the combustion processes and total combustion duration of various fuels inside the engine cylinder 


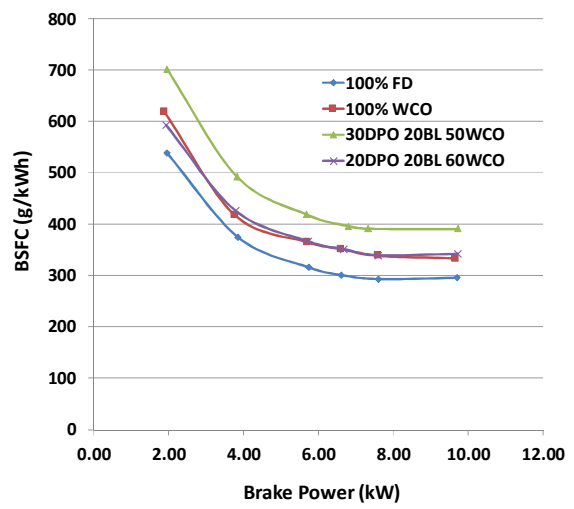

(a) brake specific fuel consumption (in $\mathrm{g} / \mathrm{kWh}$ )

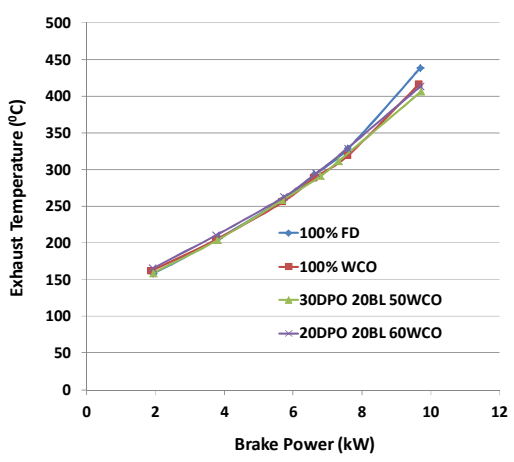

(c) variations in the exhaust gas temperatures

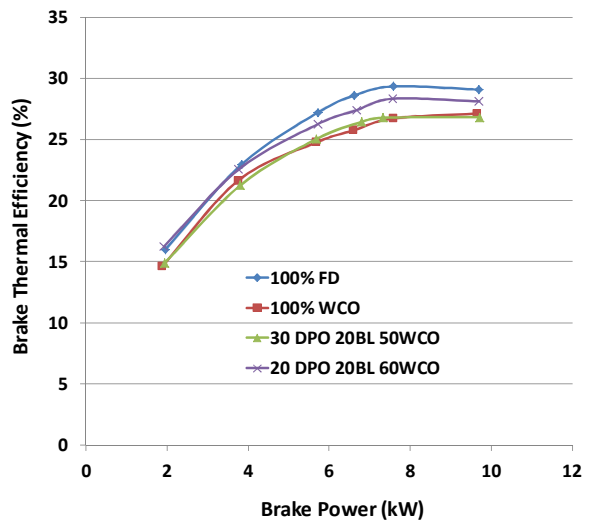

(b) thermal efficiency of all fuels

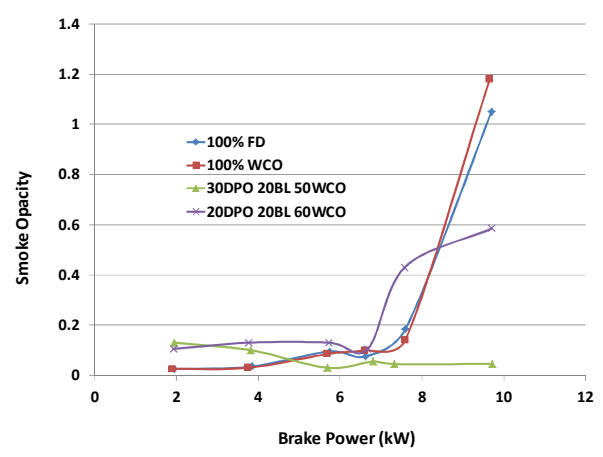

(d) variations in the smoke opacity values 


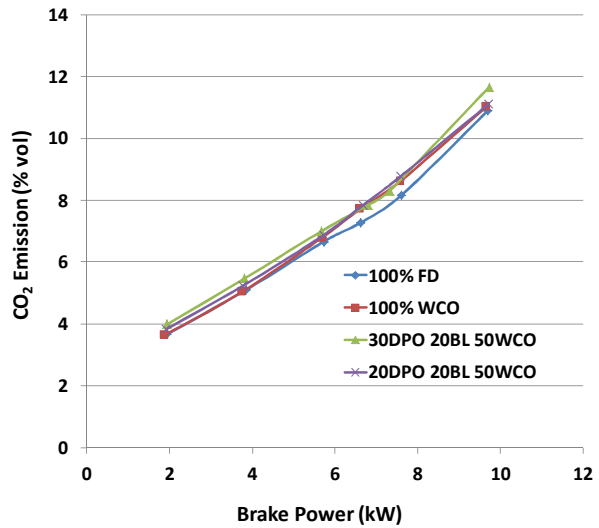

(a) variations in $\mathrm{CO}_{2}$ emissions

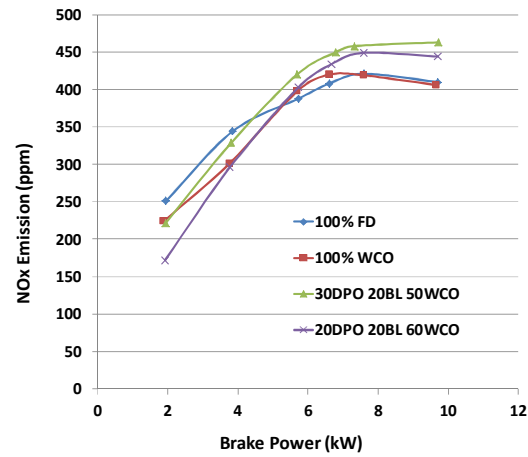

(c) comparison of the NOx emissions

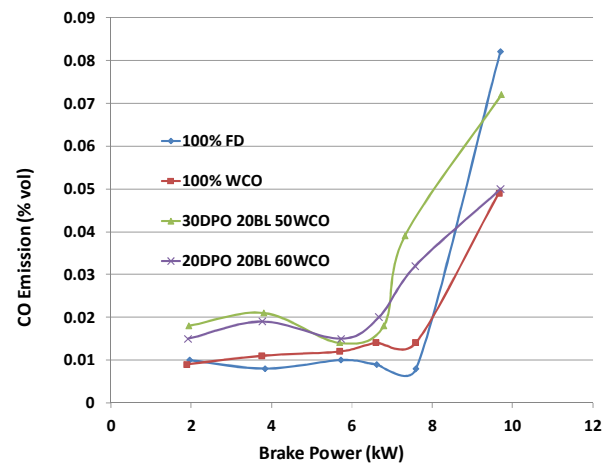

(b) variations in $\mathrm{CO}$ emissions

Figure 9 - Results showing variations in exhaust emissions as a function of engine load for all fuels 